\title{
Using Innovative Teaching Techniques and Technological Tools to Teach Grammar Points in Spanish and How They Increase Student Engagement
}

\author{
Josie Fischer \\ Thompson Rivers University
}

\begin{abstract}
The focus of this paper is how using innovative teaching techniques and technological tools enhances student's learning of grammar points in Spanish increases student engagement. The paper will examine how the use of e-cards,Voki, and comics and comic strips can be used in the Spanish language classroom to teach grammar points. For the e-cards I will discuss how it helps the students learn to write whereas the Voki will focus on the communicative aspect. The comics will be considered in terms of how they are used to help students integrate the information and create their own three panel comic strip featuring the grammar point. Because the physical separation of comics' panels mimics the gap where engaged learning takes place, knowledge is constructed and internalized while the students are having fun.
\end{abstract}

\section{Introduction}

I have been teaching $1^{\text {st }}$ and $2^{\text {nd }}$ year Spanish for 15 years at Thompson Rivers University. During this time I have used several different textbooks, and while all of them had their strengths in the concrete descriptions and presentation of grammar points, there is invariably something more that needs to be said or said in a different way. As well, an important point to consider are the different learning styles present in any classroom: "the aural, the visual, the verbal, the physical, the logical, the social and the solitary" [7]. It is impossible that one way of explaining a grammar point would suffice for all. In as much as it is possible, I found that alternative ways of teaching grammar points than traditional textbook learning in Spanish is necessary. The use of technological tools such as e-cards and Voki and comics and comic strips are one way to reach more students not only to clarify the points but to engage the students in the classroom.

\section{Background}

For many students my first year Spanish course is their first experience learning a second language. Even if others have had courses in other languages, they may have had limited success, so there is a sense of worry or fear for these students. Initially, I work to create an emotionally and intellectually safe classroom [4]. It is also important that enjoyable, interesting, and innovative strategies and techniques are sought to present challenging grammar concepts in ways that allow the students to see it as fun and less threatening. Choosing teaching materials and assignments that are at the correct level of difficulty and that are engaging and interesting must be considered [9]. For example, in recent years I have used poetry as a way to expand the students' use of vocabulary, adjectives, and grammar. The students were introduced to 4 kinds of poems: a Bio-poema, a Cinquain, a Haiku and a Name Acrostic. They were then required to write a poem for each one. Other strategies that I have used are acronyms to help the student compartmentalize the specific uses of grammar points such as POR vs PARA, SER and ESTAR and the subjunctive. While these all have proved useful, the ones that have generated the most interest from the students is the use of e-cards, Voki and comics. I have found that using them is invaluable because these types of activities "engage both instructors and students in an ongoing search for understanding, relevance, and application of new knowledge" [5]. In addition, using the e-cards, Voki and comics exemplifies the "use of media that students are already familiar with... in order to stimulate their desire to learn. If they can see how language study corresponds to their own activities, it may stimulated their desire to learn as much about the language as possible." [8] I found that almost all students have sent e-cards and can relate to comics and comic strips. Comics are familiar, comfortable and allow the student to be creative with the grammar point and really actively engage in this learning activity [9]. The introduction of Voki was a surprise in that none of my 130 students had ever heard of it but once they started using it they were quite interested.

The development of student engagement techniques has expanded as more becomes known about foreign language learners. Three characteristics of students taking languages "have been found to be consequential for language learning: motivation, anxiety, and beliefs about 
language learning." [6] In terms of motivation it is important to consider why the student is taking the language class. For example, a student that is in the class in order to fulfill a language requirement is said to have instrumental motivation whereas a student who is in the class and really wants to learn the language in order to connect with speakers of the language is said to have integrative motivation. In terms of anxiety, it has been argued (Horowitz, Horowitz and Cope (1986) that "foreign language anxiety (FLA) is a specific anxiety that some people experience when learning or using a second language. They suggest that foreign language anxiety is similar to some other well-known anxieties such as public speaking or test anxiety. Specifically, they think that FLA is related to the discomfort some people feel when their limited language proficiency keeps them from "being themselves" when using the new language....[they] are uncomfortable because they cannot express their true personality in the new language." [6] While motivation and anxiety may be more easily perceived, the final important consideration, learner beliefs about learning a language, is not. Unless the student shares that they have heard that it is more difficult to learn languages when a person is older, or that one gender is better at learning languages than the other it is almost impossible to know. The fact is though, that these beliefs (if negative) can impact the motivation and contribute to anxiety. There are several ways to manage these issues. One of them, in my experience has been to use techniques that engage the students. Because many of my students are still in their teens,(late) they are very comfortable with technology and using technological tools can help draw them out. In addition, use of these has shown to have "increased motivation, improvement in selfconcept and mastery of basic skills, more studentcentered learning and enjoyment in the learning process and more active processing resulting in higher-order thinking skills and better recall (Brownlee-Conyers, 1996; Dwyer 1996; McGrath 1998; Weiss, 1994) Additionally, there seems to be a beneficial multimedia effect, especially for low achieving students, when it is used to illustrate concepts and organize factual information (Nowaczyk, 1998). [12] The thinking is that because technological teaching techniques are student centered, they allow the students to become "active participants in the construction of new knowledge that is idiosyncratic and derived from the learner's prior experience and need to create equilibrium (i.e. find meaning or fill in an information gap) when faced with a new situation that creates cognitive dissonance." [12]

\section{Learning Grammar through E-Cards, Voki and Comics}

Every year I endeavor to introduce new techniques and technological tools that engage students and help them integrate the grammar point. It is important to select something that is appropriate for the skill being worked on (i.e writing speaking etc.), but also, the usefulness of the tool is "all in the way the activities are implemented so as to engage and foster the students own sense of agency". [3] The following discourse will explain how certain techniques and technological tools are used in my classes to help students learn to utilize and integrate grammar points and skills. In the first few weeks of the first semester the students are introduced to set expressions that allow them to initiate communication with one another. Then they are introduced to the verb SER and adjectives that are typically used with SER (such as nationality, profession, personality traits, size). They have many opportunities to practice the grammar point orally and in writing. Once they have had some practice I take them to the lab to complete the assignment using Kisseo-tarjetas which are Spanish e-cards. Although this site can be accessed from any computer anywhere I find it is helpful to the student to explain what the expectation is face- to -face. Also, by having them complete it during their lab hour I am available for any questions that may arise. After they access the site they being work on the assignment using the grammar point. In this case, it was the use of SER with adjectives to describe themselves in an e-card to a new friend. Then they send the e-cards to me for grading as a writing exercise.

Another teaching technique that I used for the first time is a program called Voki. This program allows a person to create an animated character (avatar) and to give it their own voice. The idea of the students creating a graphic representation of themselves or an alter ego and then speaking through it intrigued me particularly in terms of the shyer students in the classes. I was interested to see if it would be easier for them to speak. Again, this exercise was completed in the language lab, although like the e-cards it can be accessed through any computer anywhere once they have the username and password. Initially I showed them how to access the site and then created my own avatar and spoke a few lines in Spanish. Once the students had created their avatar they had to record themselves say three sentences in Spanish using three subject pronouns and three - ar verbs to demonstrate their understanding of the grammar point which w/verb agreements.

A final teaching technique that I use to instruct grammar points is the use of comics and comic strips and then accessing a comic generating site. One of 
the more challenging aspects of Spanish is the use of the two simple past tenses, that is, the preterit and imperfect, together in the same sentence. Explaining the reasons why and introducing 'trigger' words for the uses of each tense helps, but what is needed is some way for the students to own the knowledge. Initially, I rely on traditional presentation methods, using the textbook and generalized fill-in-the-blanks exercises. Then, once they have had some practice, I introduce comic strips that have been specially selected that show the grammar point in a familiar medium. The strips are an alternate teaching strategy whose main purpose is to "help students think about material presented during class" [1]. The strips are also authentic, that is, in the Spanish language, and because they are short they are easy to read and not overwhelming as dialogues sometimes can be. The main comics that are used are Mafalda (a strip featuring a little girl from Argentina), Condorito (a strip where the main character is an anthropomorphic Condor from Chile), and North American comics that have been translated into Spanish are also presented. Because comic strips are cultural constructs, the humour is not always easily understood; therefore, a brief explanation is given before they are presented. Initially, the students read the strips, and once they realize that they understand the use of the grammar in context, they begin to get excited and motivated for the next step. At this point I explain their assignment to them, which is that they will create their own 3 panel comic strip featuring the grammar point. They are shown how to access the MakeBeliefsComix.com website [13], a comic generating site. I have found that utilizing this site is more expedient for the students instead of expecting them to draw their own characters as most of the students are intimidated at the prospect of drawing, although some still elect to do so. Once the site is accessed, they are shown how to manipulate the characters, the talk bubbles etc., and then I create for them in class a comic so they can see exactly what is required. At this point they are usually quite eager to do the assignment. Suddenly, something as boring, and for some as scary, as grammar is transformed into something relevant and fun.

\section{Results}

All three of these instructional techniques were successful in terms of completion. In the e-cards most of the students demonstrated accurate usage of the verb SER with adjectives as well as proper use of certain set expressions that they had learned. Although it was a small sample of writing, I could see some of the students reaching to try and say more. I found the Kisseo tarjetas very useful for initializing writing with beginner students.

The use of Voki was really successful with almost $100 \%$ completion rate. The student's avatars were amazing and it was uncanny how similar they looked like the actual student. Some students opted to create alter- ego avatars which were depicted by robots, animals and even historical characters. The exercise was a communicative task and was graded on the grammatical and pronunciation of the output. Most students did very well and it was interesting to listen to some of the students who rarely speak voluntarily in class speak clearly in the recording. Perhaps being able to speak through the avatar allowed them to feel more comfortable and less threatened. Subsequent exercises that are planned for the use of Voki are to let the students use them to create dialogues either with students in the class or establishing e-pals

The comic strip exercise also had a very high completion rate in that every student submitted a comic strip. Furthermore, students had a real sense of pride about what they had created and were pleased not only to email it or to provide a hard copy to me for marking, but also to show it to their friends. Although in some cases, the comic strips had errors pertaining to other grammar concepts, what was being considered was the accuracy of use of the preterit and imperfect together in this assignment. It was noted that some students who had difficulty with other grammar that was presented throughout the course demonstrated understanding of the concept of the preterit and imperfect together in their comic strip. This is because the accessibility of the comics enabled the students to show more creatively how they understood the grammar point. The students also had fun creating the comic strips as they were engaged and "making meaning of what they [were] learning" [2].

While there are those that may not consider the use of comics a relevant strategy in the language classroom because they are considered 'entertainment, I have used it with success. This, I believe, is due in part to the idea that if a strategy engages students, then they are not just being entertained but they are also thinking [2]. Also, part of the success can be attributed by the nature of the comic strip panels which have clear boundaries around each panel. These boundaries subconsciously force the mind to engage in an alternate way of understanding what is occurring in each panel independent of the next. This is what comic theorist Scott McCloud refers to as "closure" [10], which is a complete mental jump from one panel or one concept to the next, forcing the mind to actively engage in making meaning. Producing the comic strip requires the student to be able to do more than fill-in-theblanks: it requires assimilation of the grammar point. Use of the comic strips puts the student in what Vygotsky terms the "zone of proximal development" [2], which suggests "that learning is productive when learners are operating in a situation that exposes them to concepts and ideas just slightly above their current level of development. The theory, applied to 
student engagement, suggests that engaged learning occurs in the gap between a learner's current understanding and potential of understanding" [2]. This is fundamental: the "gap" between the panels that causes the students to enact closure is the same "gap" that creates "engaged learning". The students become owners and creators of their knowledge, which enables better understanding of the grammar point.

Using comics and comic strips to teach grammar points has had positive results and high student engagement, and, because "in terms of learning content, students are more likely to remember material in which they have made an emotional investment" [2], they will be used again. Comics and comic strips as learning activities are successful because "students are engaged on a cognitive level (they are thinking about what they are doing), an affective level (they enjoy what they are doing and give it their full attention), and when possible and appropriate' on a kinesthetic level (they apply the theoretical and abstract by actually doing a physical" [2]. Because comics engage the learner in the actual process as well as on all levels of learning, they hold immense potential for the teaching of grammar points.

\section{Conclusion}

Integrating tools such as e-cards, Voki and comics have proven to be fun additions to the presentation of grammar concepts in my Spanish classes. They engage and motivate students because while the technology or tool is sometimes familiar to the students, such as the e-card and comics, it is unusual to see them in the classroom. And, allowing the students to create an e-card, and avatar and their own strip expresses their assimilation of the grammar point to the level required. In addition, I can see other uses for these three techniques in the language class. For example, the students might be asked to write a more expanded e-card that they will send to a native speaker of Spanish. In terms of the Voki, I plan to encourage them to practice recording themselves on more grammar points as well as organizing the students into e-pals from within their own section and some of the other sections. For the comics, the students might be asked to create strips in pairs or groups and then present them to the class. As an initial exercise, they could be given comic strips that have been cut apart, and then working in pairs or groups they would reconstruct the strip in the correct sequence. This exercise would encourage the student to focus on the dialogue in each of the panels to decide which event occurred in what order. "much of the responsibility for success at language learning rests with individual learners and with their ability to take full advantage of opportunities to learn" [11], using alternative teaching techniques such as the three discussed in this paper, engage students and promote active learning which reflects a "contemporary paradigm shift in post- secondary education...from providing instruction to producing learning." [5] As well, they make the grammar points not only more accessible to the students, but also more relevant which, in turn, makes them more meaningful to the students, and that makes it fun.

\section{References}

[1] Alternative Teaching Strategies New Mexico Space Grant,www.spacegrant.nmsu.edu/NMSU/fac_dev/grasp_al ternative.pdf

[2] Barkley, EF, Student Engagement Techniques, JosseyBass, San Fransisco, 2010.

[3] Blake, Robert,J, Brave New Digital Classroom: Technology and Foreign Language Learning, Georgetown University Press, Washington, DC, 2008

[4] de Frondenill, T. Ten Steps to Better Student Engagement, www.edutopia.org/project-learning-teachingstrategies.

[5] Fisher, Roger, Instructors Guide to Classroom Engagement, Nelson Education Ltd,. 2011

[6] Foreign Language Teaching Methods, The University of Texas at Austin, www.coerll.utexas.edu/methods/

[7] Learning Styles www.learning-stylesonline.com/overview

[8] Lewis, Jared, Instructional Strategies for Spanish Language Teachers, www.ehow.com/way_5900312_instructor

[9] Managing the Learning Environment-Strategies for Increasing Student Engagement, www.afcec.org/tipsfor teachers/tips_b4.html

[10] McCloud, S, Understanding Comics: The Invisible Art, Harper Collins, New York, 1993.

[11] Oxford, RL, Language Learning Strategies, Heinle and Heinle, Boston, 1990.

[12] Student Perceptions on Language Learning in a Technological Environment: Implications for the New Millenium, Language, Learning \& Technology, http://lit.msu.edu/vil6num1/steppgreany/

[13] Zimmerman B, How to Play with MakeBeliefsComix. com, www.makebeliefscomix.com 